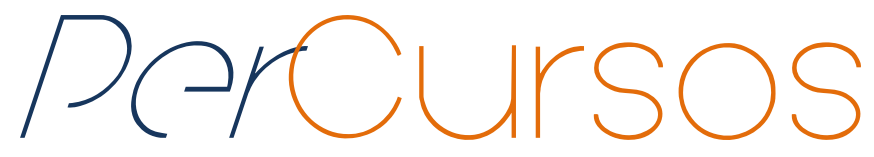

\title{
Aquisição dos verbos irregulares do Português Brasileiro
}

\begin{abstract}
Resumo
Esse artigo vem unir-se aos trabalhos que versam sobre a aquisição da classe verbal irregular do Português Brasileiro (PB), sob o escopo de correntes teóricas do ramo da linguística aplicada, com o objetivo de investigar o processo da regularização verbal e sua possível relação com os modos verbais Indicativo e Subjuntivo. Para isso, traçamos particularidades tanto do Indicativo, como do Subjuntivo, por meio de pesquisa na literatura da área, a fim de verificar seu uso na língua por crianças falantes nativas de PB com idades entre 06 e 09 anos, alunos, portanto, do ensino Fundamental I.
\end{abstract}

Palavras-chave: Aquisição Verbal Irregular. Língua Portuguesa. Estudo. Ensino.

\author{
Tamires Pereira Duarte Goulart \\ Mestra em Linguística Aplicada \\ pela Univ. Católica de Pelotas - \\ UCPel. Professora da Rede \\ Municipal de Canguçu - RS e \\ Tutora a distância da Univ. \\ Federal de Pelotas - UFPel. \\ Brasil \\ tamirespdgoulart@gmail.com
}

\section{Para citar este artigo:}

GOULART. Tamires Pereira Duarte. Aquisição dos verbos irregulares do Português Brasileiro. Revista

PerCursos, Florianópolis, v. 18, n.37, p. 108 -129, maio/ago. 2017.

\section{DOI: $10.5965 / 1984724618372017108$}

http://dx.doi.org/10.5965/1984724618372017108 


\title{
Acquisition of the irregular verbs of Brazilian Portuguese
}

\begin{abstract}
This article comes join itself to the researches that deals with the acquisition of the irregular verbal class of Brazilian Portuguese (PB), under the scope of the theoretical currents of Applied Linguistics, with the aim of investigating the verbal regularization process and its possible relation between the Indicative verbal mode and Subjunctive verbal mode. For this, we describe particularities as the Indicative as the Subjunctive, through research in the literature of the area, in order to verify their use in the language by native speakers children of PB between the ages 06 and 09 years old, students, therefore, of elementary school I.
\end{abstract}

Keywords: Irregular Verbal Acquisition. Portuguese Language. Study. Teaching. 


\section{Introdução}

Uma característica que as línguas do mundo compartilham é o fato de serem organizadas a partir de estruturas linguísticas regulares e irregulares. Diante disso, no processo de aquisição da linguagem, a criança precisa adquirir as unidades (morfológicas, fonológicas, sintáticas, semânticas) que constituem cada uma dessas estruturas, a partir do input linguístico que recebe. A aquisição da classe verbal irregular, por exemplo, apresenta alta complexidade para os falantes dos mais variados sistemas linguísticos, por exigir a aquisição de diferentes componentes dentro do sistema, como por exemplo, da morfologia e da fonologia (GOULART, 2015).

Nesse sentido, este estudo centra-se no processo de aquisição dos verbos irregulares do Português Brasileiro (PB), tendo em vista que no Brasil, ainda são poucos os trabalhos que investigam a aquisição dessa classe verbal. O PB conta em sua gramática com a presença de verbos regulares e irregulares. Os verbos regulares são aqueles cujas conjugações mantêm inalterados os seus radicais e que seguem o padrão geral na adjunção de morfemas flexionais, como ocorre com o verbo cantar em toda a sua conjugação, como por exemplo, cant-o, cant-ava, cant-ara, cant-asse.

Os verbos irregulares, no entanto, são aqueles em que, nas suas conjugações, há mudança no radical, como é o caso do verbo dizer e suas respectivas flexões - digo, dizes, diz, disse; ou, ainda, são aqueles que não seguem os padrões mais amplos/gerais determinados pela gramática da língua para seguirem padrões específicos, apresentando, por exemplo, alterações quanto à estrutura mórfica flexional. Um exemplo dessa última ocorrência pode ser observado no verbo saber, cuja conjugação no Presente do Indicativo apresenta as formas: sei, sabes, sabe.

No processo de aquisição verbal da classe irregular, pesquisas brasileiras (LORANDI, 2006; GOULART, 2015) apontam que as crianças ainda em fase de aquisição desse sistema linguístico podem apresentar em suas produções formas verbais regularizadas. Isto é, conjugações para os verbos irregulares que seguem o padrão de flexão dos verbos regulares do PB, como por exemplo, pido pedo do verbo "pedir" para a conjugação peço; mido medo do verbo "medir" para a conjugação meço (GOULART, 2015). Para Lorandi (2010, p. 8), “a criança em fase de aquisição utiliza recursos do 
subsistema morfológico de sua língua, de forma coerente com o padrão sistêmico, pois não cria morfemas gramaticais inexistentes, mas ajusta-os aos radicais que ela conhece e que estão disponíveis no momento da produção". Nesse contexto, a autora busca destacar que a sistematização que privilegia a regularidade de verbos irregulares evidencia uma gramática em construção, "o que afasta a ideia de que o sujeito esteja cometendo um erro e considera, dessa forma, o fato de serem formas verbais variantes, concorrentes com as formas da língua-alvo" (LORANDI, 2010, p. 10).

Sob esse viés, o presente artigo discute o processo da regularização verbal como sendo uma fase da aquisição da classe verbal irregular e centra sua investigação na empregabilidade destas formas regularizadas, considerando os modos Indicativo e Subjuntivo. São modos verbais que apresentam em suas conjugações alternâncias fonológicas consonantais (em medir, por exemplo, /d/ alterna-se com /s/, como em meço). Assim, tanto o indicativo como o subjuntivo são modos verbais, em que as alternâncias são um fenômeno recorrente nas flexões, o que pode contribuir para que a aquisição verbal irregular seja considerada uma classe de aquisição tardia.

Traçamos, nesse âmbito, particularidades desses modos verbais, investigando seu uso na língua por alunos do Ensino Fundamental I, na faixa etária de 06 a 09 anos de idade. Além disso, buscamos, nesse sentido, voltar atenção para o ensino dos verbos irregulares nas escolas, principiando-nos da pesquisa de Goulart (2015), a qual aponta que crianças, no mínimo, até os 09 anos de idade encontram-se em fase de aquisição do sistema verbal irregular da Língua Portuguesa, o que caracteriza esses verbos como um segmento da língua de aquisição tardia.

\section{Particularidades dos modos indicativo e subjuntivo}

As diferentes línguas modernas diferenciam a categoria dos verbos nos planos paradigmáticos do tempo, do modo e da voz (Câmara Júnior, 1956). Em relação aos verbos do PB, o modo verbal relaciona-se ao julgamento que o falante pode fazer sobre a voz verbal, considerando o real, o irreal, o possível ou o necessário (CASTILHO, 2012). 
O PB, bem como outras línguas, conta com três diferentes modos: o Indicativo, o Subjuntivo e o Imperativo. Todos eles, segundo Castilho (2012), apresentam uma propriedade discursiva comum, a de representarem atos de fala. Esse autor ainda revela que o modo se gramaticalizou em Português por diferentes meios, sendo:

(i) por meio de sufixos modo-temporais, no caso do indicativo, do subjuntivo e do imperativo; (ii) por meio de morfemas -vocábulos, ou seja, os verbos auxiliares poder, dever, querer, entre outros; (iii) por meio de outros operadores de modalização. A representação do tipo (i) aparece no sintagma verbal simples, a representação do tipo (ii), no sintagma verbal composto, e a representação do tipo (iii), em expressões complexas (CASTILHO, 2012, p. 397, 398 )

Analisamos, diante disso, nessa seção, as particularidades dos modos Indicativo e Subjuntivo, por serem, aqui, fatores que podem estar correlacionados à regularização no processo de aquisição do sistema verbal irregular do PB. Para tal, destacamos que o modo indicativo manifesta a atitude de certeza relativa do falante perante o processo que enuncia e aparece acumulado com as noções de presente, pretérito ou futuro.

Para Souza \& Silva e Koch (2009), o indicativo presente (Id Pr) expressa um processo paralelo ao ato de fala, indicando um fato costumeiro e habitual ${ }^{1}$. O pretérito ou passado (Id Pt), por sua vez, revela um processo anterior ao ato de fala, manifestando-se através do imperfeito (Id Pt1), do pretérito perfeito (Id Pt2) e do mais-que-perfeito (Id Pt3). O futuro (Id Ft) exprime um processo posterior, seja ao momento em que se fala, ou a um processo passado e, por isso, divide-se em futuro do presente (Id Ft1) e futuro do pretérito (Id Ft2).

Reichenbach (1947) considera para o inglês que os tempos verbais são determinados por meio do tempo de fala, do tempo da situação e do tempo de referência de um dado enunciado. Freitag (2005) exemplifica o pressuposto de Reichenbach, conforme mostra a figura (1):

\footnotetext{
${ }^{1}$ No plano discursivo da língua, os tempos verbais podem veicular, além dessas referidas, outras noções.
} 
Figura 1 - Exemplo de Freitag (2005) para exemplificar a teoria de Reinchenbach (1947)

(1) Após uma dura batalha em Karbala, a $3^{a}$ Divisão de Infantaria dos EUA penetrou na zona vermelha no dia $1^{\circ}$ de abril, sem enfrentar maior resistência. (col. 2 lin. 8-11) $)^{5}$

S: penetrou

R: $1^{0}$ de abril

F: $13 / 04 / 2003$ data de publicação do jornal

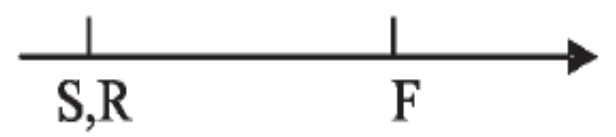

Fonte: Freitag (2005)

Observa-se no exemplo da figura (1) que há uma situação (S) anterior ao tempo de fala, representado pelo verbo "penetrou”, um tempo de referência (R) caracterizado por $1^{\circ}$ de abril e um ato de fala (F), marcado pela data de publicação do jornal.

Através de seus variados tempos, a representação morfológica do Indicativo, manifestada por sufixos, representa cumulativamente além do modo, os tempos verbais, os quais, portanto, são denominados de sufixos modo-temporais (CASTILHO, 2012, p. 393).

O modo Subjuntivo, analogamente ao Indicativo, tem sua manifestação morfológica por meio de sufixos. O que difere os dois modos, no entanto, é a capacidade de o Subjuntivo expressar atitude de incerteza, possibilidade ou dúvida. De acordo com Souza \& Silva e Koch (2009), a oposição Indicativo/Subjuntivo é mais de modalidade que de tempo, sendo que os tempos do Subjuntivo não apresentam noção de época tão definida como os do indicativo o fazem.

Em seu livro “Estrutura da Língua Portuguesa”, Câmara Júnior (1970) descreve que o modo do Subjuntivo ou Conjuntivo conta com os três tempos verbais, sendo o presente ( $\mathrm{Sb} \mathrm{Pr}$ ), o pretérito imperfeito (Sb Pr) e o futuro (Sb Ft), entretanto, para esse autor, a divisão tripartida não é fiel à realidade linguística, tendo em vista, que, na verdade, existem duas divisões dicotômicas que se complementam: 
...De um lado, temos uma oposição entre presente e pretérito, em que o pretérito é a forma marcada. Indica diretamente o passado nas orações independentes precedidas do advérbio talvez. [...] De outro lado, temos uma oposição entre pretérito e futuro nas orações subordinadas que estabelecem uma condição prévia do que se vai comunicar (CÂMARA JÚNIOR. 1970, p. 101)

Cabe aqui, ressaltar que, segundo Câmara Júnior (1970), o Subjuntivo, incluindo o Imperativo, marca uma posição subjetiva do falante em relação ao processo verbal comunicado. "Não percebemos essa ocorrência quanto ao modo Indicativo, porém não afirmamos sua inexistência" (CÂMARA JÚNIOR, 1970).

O Subjuntivo muitas vezes pode aparecer acompanhado de advérbios como, por exemplo, talvez; de conjunções como quando, para marcar o futuro; ou ainda, da partícula se, a fim de indicar o pretérito imperfeito.

\section{Metodologia e caracterização dos instrumentos}

Com o objetivo de identificarmos na língua o uso do Indicativo e do Subjuntivo e sua ação sobre o processo de regularização da classe verbal irregular do PB, investigamos um grupo de alunos brasileiros, cuja faixa-etária está entre 06 e 09 anos de idade. Os sujeitos são alunos de uma escola da rede pública municipal de ensino, naturais da cidade de Canguçu, município situado na região sul do Rio Grande do Sul/Brasil ${ }^{2}$.

Os 16 sujeitos entrevistados, todos alfabetizados, foram divididos em quatro grupos, os quais estão diretamente atrelados ao nível escolar e à idade em que os alunos se encontram. Dessa forma, integraram a esta pesquisa, 04 alunos de 06 anos do $1^{\circ}$ ano do Ensino Fundamental I, 04 alunos de 07 anos do $2^{\circ}$ ano do Ensino Fundamental I, 04 alunos de 08 anos do $3^{\circ}$ ano do Ensino Fundamental $I$ e 04 alunos de 09 anos do $4^{\circ}$ ano do Ensino Fundamental I.

\footnotetext{
${ }^{2}$ Cabe salientar que os informantes não são alunos da pesquisadora e são todos pertencentes a mesma escola, que possui a maioria de seus discentes da classe média baixa. O grupo de alunos também foi subdividido dentro de cada faixa-etária em relação ao sexo.
} 
Para a obtenção do corpus deste estudo, foram propostos dois tipos de instrumentos, os quais são testes orais, criados pela pesquisadora, cujo foco está centrado na produção de formas verbais irregulares na $1^{\mathrm{a}}$ e na $2^{\mathrm{a}}$ pessoa do singular do Presente do Indicativo e na $1^{\mathrm{a}}$ e na $2^{\mathrm{a}}$ pessoa do singular do Presente do Subjuntivo.

Os verbos irregulares analisados formaram um conjunto de dez, sendo eles: “dizer, fazer, satisfazer, trazer, poder, ter, perder, medir, ouvir e pedir”. Explicamos, nesse âmbito, a preferência por esses vocábulos, levando em conta que acreditamos serem os mais familiares às crianças, o que facilita o diálogo e a naturalidade na aplicação dos instrumentos.

O verbo satisfazer, por exemplo, tem grande probabilidade de não ser tão comum no input dos sujeitos, porém, por ser um derivado do verbo fazer, houve a pressuposição de que seu uso no teste poderia não apresentar complexidade para as crianças.

Salientamos que, dentre os dez verbos selecionados para esta pesquisa, nove têm a irregularidade atestada por alternância do radical durante a sua conjugação, sendo que apenas um - o verbo ter - tem a irregularidade atribuída por desviar-se do paradigma em sua conjugação. Destacamos que a irregularidade que a conjugação do verbo ter apresenta quanto ao paradigma implica alternância consonantal e vocálica.

Os instrumentos também contaram com o estímulo da produção de verbos regulares, que assumiram a posição de "distratores" para desfocar o objetivo central da pesquisa, que está voltada à conjugação da classe irregular. Para tal, os verbos regulares escolhidos foram "abastecer, agradecer, aquecer, beber, aplaudir, assistir, assumir e admitir".

Dito isso, ressaltamos que tanto os verbos irregulares, quanto os regulares foram selecionados atentando ao fato de pertencerem à segunda e terceira conjugação verbal, respectivamente, terminadas em -er e -ir, pois, em PB, a primeira conjugação verbal -ar possui um número restrito de verbos irregulares, como por exemplo, os verbos “dar" e "estar".

Pensando em modalidades de instrumento que estimulassem o emprego dessas conjugações, criando situações naturais de fala compatíveis com a proposta da 
investigação, o primeiro instrumento foi constituído de frases com lacunas a serem completadas pelos informantes na forma de slides, na tela de um laptop. O primeiro slide possuía uma frase, como por exemplo, “medir a altura é legal!”; o segundo slide, então, continha as frases a serem completadas pelo aluno, individualmente, tais como: "Eu sempre minha altura; Papai quer que eu minha altura".

O Instrumento I contou com 10 slides com a exposição de verbos irregulares, sendo que, em cada um deles, foram apresentadas 06 diferentes sentenças com lacunas a serem preenchidas, o que totalizou 60 espaços a serem completados com o uso oral de verbos irregulares por cada informante, além das produções das conjugações dos verbos regulares. Salientamos que os alunos foram convidados a completarem as lacunas de forma oral, não precisando escrever suas respostas. Todas as enunciações foram gravadas e, posteriormente, transcritas pela pesquisadora.

No segundo instrumento, com o propósito de investigar as mesmas conjugações realizadas no primeiro instrumento, com as mesmas pessoas e tempos verbais investigados, focalizamos essas produções por meio de histórias com lacunas que foram completadas pelo sujeito, oralmente. Aqui, novamente, destacamos que as falas de cada aluno foram gravadas e transcritas em um segundo momento. A aplicação do instrumento II deu-se no período de um mês posterior à aplicação do instrumento I, sendo que, nessa coleta, possibilitou-se o uso verbal de forma contextualizada, de acordo com o enredo das histórias, as quais foram expostas aos informantes em papel ofício. Com esse instrumento, obtivemos 96 produções de cada verbo analisado; tem-se um exemplo desse segundo recurso em (2): 


\section{Medir}

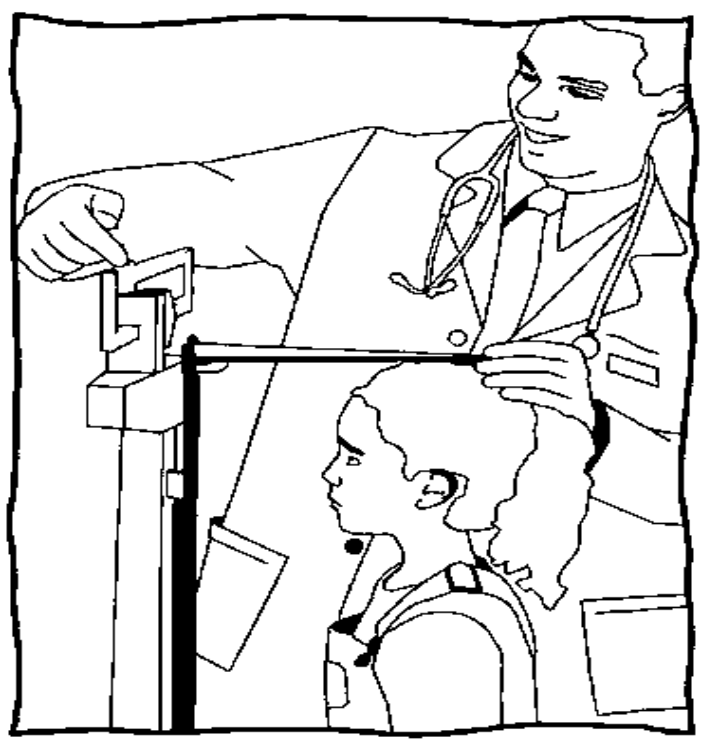

Nessa foto eu estou medindo minha altura.

Ontem eu fui ao médico e minha altura.

Ele me disse que atualmente eu um metro e cinquenta centímetros e espera que, na próxima consulta, eu mais ou menos um metro e cinquenta e cinco centímetros.

- Sabias, mãe, que crescemos enquanto dormimos? Quanto tu mamãe? Ontem tu mais do que eu? Espero que tu não mais do que um metro e setenta, pois será difícil te alcançar.

Fonte: A autora 


\section{Análise dos dados: uma aproximação dos modos verbais ao ensino de língua} portuguesa

Meira (2009, p. 2) discute que "a variação no uso dos modos, especificamente do subjuntivo, em português é um fato incontestável”. A autora ainda afirma que "o indicativo por se referir a eventos reais tende a ser mais usado na comunicação, podendo ser definido, portanto, como modo morfologicamente não-marcado na língua (MEIRA, 2009, p. 2)".

Nossos dados revelaram que o modo subjuntivo por ser de caráter marcado na língua apresentou maior tendência de conjugações regularizadas pelos sujeitos. As tabelas que seguem mostram em percentuais a produção de conjugações dos verbos irregulares de forma regularizada pelos sujeitos nos dois instrumentos aplicados.

Tabela 1 - Análise em relação ao Tempo e Modo Verbal - Instrumento I

\begin{tabular}{|c|c|c|c|c|c|c|c|c|c|c|c|c|c|c|c|c|c|}
\hline \multirow[t]{2}{*}{$\begin{array}{l}\text { Tempo } \\
\text { Verbal }\end{array}$} & \multicolumn{16}{|c|}{$\begin{array}{l}\text { Ocorrências das formas regularizadas de acordo com tempo e modo verbal } \\
\text { (Porcentagem) - Instrumento I }\end{array}$} & \multirow[t]{2}{*}{\begin{tabular}{|l|} 
Total em \\
percentuais \\
das formas \\
regularizadas
\end{tabular}} \\
\hline & \multicolumn{16}{|c|}{ Informantes } & \\
\hline & 01 & 02 & 03 & 04 & 05 & 06 & 07 & 08 & 09 & 10 & 11 & 12 & 13 & 14 & 15 & 16 & $\%$ \\
\hline $\begin{array}{l}\text { Pres. } \\
\text { Ind. }\end{array}$ & $35 \%$ & $20 \%$ & $25 \%$ & $20 \%$ & $30 \%$ & $15 \%$ & $20 \%$ & $15 \%$ & $5 \%$ & $10 \%$ & $35 \%$ & $20 \%$ & $0 \%$ & $10 \%$ & $20 \%$ & $5 \%$ & $17,8 \%$ \\
\hline $\begin{array}{l}\text { Pret. } \\
\text { Perf. } \\
\text { Ind. }\end{array}$ & $10 \%$ & $10 \%$ & $0 \%$ & $10 \%$ & $10 \%$ & o\% & $0 \%$ & $0 \%$ & $0 \%$ & $5 \%$ & $15 \%$ & $0 \%$ & $\rho \%$ & $5 \%$ & $0 \%$ & $0 \%$ & $4 \%$ \\
\hline $\begin{array}{l}\text { Pres. } \\
\text { Subj. }\end{array}$ & $55 \%$ & $30 \%$ & $30 \%$ & $30 \%$ & $55 \%$ & $30 \%$ & $65 \%$ & $30 \%$ & $30 \%$ & $10 \%$ & $50 \%$ & $40 \%$ & $10 \%$ & $30 \%$ & $30 \%$ & $30 \%$ & $34,6 \%$ \\
\hline
\end{tabular}

Fonte: A autora 
Tabela 2 - Análise em relação ao Tempo e Modo Verbal - Instrumento II

\begin{tabular}{|l|l|l|l|l|l|l|l|l|l|l|l|l|l|l|l|l|l|}
\hline $\begin{array}{l}\text { Tempo } \\
\text { Verbal }\end{array}$ & \multicolumn{1}{|c|}{ Ocorrências das formas regularizadas de acordo com tempo e modo verbal (Porcentagem) - } & $\begin{array}{c}\text { Total em } \\
\text { percentuais } \\
\text { das formas } \\
\text { regularizadas }\end{array}$ \\
\hline & 01 & 02 & 03 & 04 & 05 & 06 & 07 & 08 & 09 & 10 & 11 & 12 & 13 & 14 & 15 & 16 & $\%$ \\
\hline $\begin{array}{l}\text { Pres. } \\
\text { Ind. }\end{array}$ & $43,7 \%$ & $25 \%$ & $25 \%$ & $18,7 \%$ & $31,2 \%$ & $25 \%$ & $25 \%$ & $31,2 \%$ & $6,2 \%$ & 0 & $31,2 \%$ & $25 \%$ & $0 \%$ & $18,7 \%$ & $18,7 \%$ & $6,2 \%$ & $20,6 \%$ \\
\hline $\begin{array}{l}\text { Pret. } \\
\text { Perf. } \\
\text { Ind. }\end{array}$ & $12,5 \%$ & $12,5 \% 10 \%$ & $0 \%$ & $0 \%$ & $6,2 \%$ & $0 \%$ & $0 \%$ & $6,2 \%$ & $6,2 \%$ & $0 \%$ & $0 \%$ & $0 \%$ & $6,2 \%$ & $0 \%$ & $0 \%$ & $3,7 \%$ \\
\hline $\begin{array}{l}\text { Pres. } \\
\text { Subj. }\end{array}$ & $62,5 \%$ & $50 \%$ & $37,5 \%$ & $50 \%$ & $68,7 \%$ & $50 \%$ & $56,2 \%$ & $25 \%$ & $25 \%$ & $31,2 \%$ & $50 \%$ & $50 \%$ & $18,7 \%$ & $37,5 \%$ & $25 \%$ & $31,2 \%$ & $43,3 \%$ \\
\hline
\end{tabular}

Fonte: A autora

Os informantes operaram com $17,8 \%$ de morfemas verbais regularizados no Presente do Indicativo, 4\% no Pretérito Perfeito do Indicativo e 34,6\% no Presente do Subjuntivo, no instrumento I.

No instrumento II, as formas regularizadas totalizaram para o Presente do Indicativo 20,6\%, para o Pretérito Perfeito do Indicativo 3,7\% e para o Presente do Subjuntivo 43,3\%. Destacamos, aqui, que as produções do tempo "pretérito perfeito do indicativo" não são alvo de análise neste artigo, por isso não serão discutidas nesse momento, apenas descritas.

Os dados apontaram, nos dois instrumentos, que o modo Subjuntivo (Presente do Subjuntivo) apresenta maior instabilidade quanto à sua flexão, em um percentual que se mostra cerca do dobro daquele alcançado com relação ao Presente do Indicativo.

Acreditamos estar esse fato relacionado à complexidade que envolve a aquisição da morfofonologia do PB e ao fato de ser o modo verbal (Subjuntivo) considerado marcado na língua, em conformidade com Meira (2009). Ou seja, há na estrutura da língua uma marcação que atinge o subjuntivo como um todo (formas regulares e irregulares) por oposição ao indicativo como um todo; o subjuntivo é por exemplo, "um 
modo verbal empregado em orações subordinadas, o que implica a construção de um período composto por subordinação e que exige também maior complexidade sintática a tal ponto que, no uso oral da língua, mesmo por adultos, é de baixa frequência" (GOULART, 2015, p. 124).

Assim, esse modo destaca-se na produção das formas não padrão (regularizadas) nas flexões das crianças entre 06 e 09 anos de idade.

O modo verbal mais marcado na língua, nesse sentido, é suscetível de maior possibilidade de variação pelos informantes desta pesquisa, em relação à forma padrão.

Nesse âmbito, Meira (2009, p. 3) destaca que:

O subjuntivo serve literalmente para subordinar, por isso tem seu emprego, por excelência, numa oração subordinada. No entanto, esse modo verbal não é empregado em todos os casos de subordinação; ao contrário, em muitas orações subordinadas usa-se preferencialmente o indicativo, e o modo subjuntivo é empregado, muitas vezes, em orações denominadas independentes ou absolutas.

Os falantes nativos de PB e de outras línguas do mundo têm a predisposição para empregar em suas produções linguísticas o menos marcado, que neste artigo, indubitavelmente, é o modo indicativo. Além disso, diante dos dados, verificamos que a maior produtividade do modo indicativo, em acordo com o padrão da língua, pode estar relacionado ao fato de as crianças serem pouco expostas às situações de fala que envolvam o modo subjuntivo. Isso poderia estar protelando o aprendizado das formas verbais irregulares do subjuntivo, o que implicou, nesta pesquisa, o processo de regularização em prevalência no Subjuntivo.

Para o Presente do Indicativo, os dados podem ser considerados relevantes, baseando-se em estudos (YAVAS e CAMPOS, 1988; SANTOS e SCARPA, 2003) que consideram esse tempo verbal como um dos primeiros a ser adquirido pelos falantes nativos de PB. 
Nesse sentido, podemos inferir que, embora seja um tempo precocemente empregado pelos sujeitos, os segmentos irregulares do Presente do Indicativo, que se realizam com alternâncias consonantais são complexos para as crianças em fase de aquisição. Assim, validamos nossa afirmação inicial, em conformidade com Goulart (2015), de que os alunos, no mínimo até o $5^{\circ}$ ano do Ensino Fundamental I, ainda estão em fase de aquisição da classe verbal irregular do PB. Isso contribui para que essa aquisição seja caracterizada como tardia, em se tratando de aquisição verbal da língua portuguesa.

Por meio das tabelas (1) e (2) evidenciamos ainda que as regularizações permaneceram em ambos os instrumentos até a mais alta faixa etária estudada. $O$ percentual do Instrumento II é mais alto comparado ao percentual do Instrumento I, embora os resultados tendam a ser equilibrados, no entanto, chama atenção que algumas regularizações ocorreram apenas na aplicação do instrumento II. Tal fato vem reforçar a hipótese de que crianças, mesmo em etapa subsequente à fase inicial da linguagem, continuam apresentando o fenômeno de regularização da classe irregular do português e, devido a isso, encontram-se, ainda, aos 09 anos de idade, em aquisição da língua no que tange à classe verbal irregular.

Na tabela (3), descrevemos alguns dados de regularização verbal produzidos pelos sujeitos, observando-se a idade e o tipo de produção realizada em cada modo verbal:

Tabela 3 - Tipo de regularização por idade dos informantes

\begin{tabular}{|c|c|c|}
\hline Faixa-etária & $\begin{array}{l}\text { Regularizações- } \\
\text { Modo Indicativo }\end{array}$ & $\begin{array}{l}\text { Regularizações- } \\
\text { Modo subjuntivo }\end{array}$ \\
\hline 06 anos de idade & $\begin{array}{l}\mathrm{Fa}[\mathrm{z}] \mathrm{o}, \text { satisfa[z]o, tra[z]o, tra[z]i, } \\
\operatorname{tra}[\mathrm{z}] \mathrm{eu}, \operatorname{per}[\mathrm{d}] \mathrm{o}, \mathrm{p} \varepsilon[\mathrm{d}] \mathrm{o}, \mathrm{m \varepsilon}[\mathrm{d}] \mathrm{o}, \\
\mathrm{mi}[\mathrm{d}] \mathrm{o}, \mathrm{ou}[\mathrm{v}] \mathrm{o}, \mathrm{o}[\mathrm{v}] \mathrm{o}\end{array}$ & $\begin{array}{l}\mathrm{Fa}[\mathrm{z}] \mathrm{a} \text {, satisfa[z]a, per[d]a, } \\
\mathrm{mi}[\mathrm{d}] \mathrm{a}, \text { ou[v]a, o[v]a, pe[d]a, } \\
\mathrm{p}[\mathrm{d}] \mathrm{a}, \operatorname{tra}[\mathrm{z}] \mathrm{a} ;\end{array}$ \\
\hline 07 anos de idade & $\begin{array}{l}\text { Satisfa[z]o, tra[z], tra[z]o, per[d]o, } \\
\mathrm{m \varepsilon}[\mathrm{d}] \mathrm{o}, \mathrm{me}[\mathrm{d}] \mathrm{o}, \mathrm{ou}[\mathrm{v}] \mathrm{o}, \mathrm{ou}[\mathrm{z}] \mathrm{o} \\
\mathrm{o}[\mathrm{v}] \mathrm{o}, \mathrm{p} \varepsilon[\mathrm{d}] \mathrm{o}, \mathrm{pi}[\mathrm{d}] \mathrm{o}, \mathrm{fa}[\mathrm{z}] \mathrm{o}\end{array}$ & $\begin{array}{l}\text { Satisfa[z]a, tra[z]a, per[d]a, } \\
\text { me[d]a, mi[d]a, me[d]a, ou[v]a, } \\
\text { ou[z]a, o[v]a, pe[d]a, pi[d]a, } \\
\text { pe[d]a, po[d]a; }\end{array}$ \\
\hline 08 anos de idade & $\begin{array}{l}\text { O[v]o, ou[z]o, tra[z]i, tra[z]o, } \\
\operatorname{per}[d] o, \operatorname{fa}[z] o, \text { satisfa[z]o, me[d]o, } \\
\operatorname{p\varepsilon [d]o;}\end{array}$ & $\begin{array}{l}\text { Mi[d]a, me[d]a, o[v]a, ou[v]a, } \\
\text { pi[d]a, pe[d]a, pe[d]a, pe[d]o, } \\
\text { per[d]a, fa[z]a, satisfa[z]a, } \\
\text { ou[z]a; }\end{array}$ \\
\hline 09 anos de idade & $\begin{array}{l}\operatorname{Per}[\mathrm{d}] \mathrm{o}, \mathrm{ou}[\mathrm{v}] \mathrm{o}, \mathrm{o}[\mathrm{v}] \mathrm{o}, \operatorname{tra}[\mathrm{z}] \mathrm{i}, \\
\text { satisfa[z]o, me[d]o, pe[d]a; }\end{array}$ & $\begin{array}{l}\text { Mi[d]a, me[d]a, me[d]a, pi[d]a, } \\
\text { per[d]a, ou[v]a, o[v]a, tra[z]a; }\end{array}$ \\
\hline
\end{tabular}

Fonte: $A$ autora 
A tabela acima descreve algumas das formas produzidas pelos sujeitos respeitando cada faixa-etária analisada, sendo que foram produções, as quais se manifestaram nos dois instrumentos; ressaltamos, ainda, que todos os informantes realizaram formas verbais regularizadas.

As regularizações, apresentadas na tabela 3, têm, entre parênteses, a consoante que não concretizou a alternância fonológica, e devido a isso, manteve-se na fala da criança fiel ao radical do verbo, como ocorre nas conjugações dos verbos regulares. Ou seja, quando o sujeito falou "ou[v]a, ele manteve-se fiel ao radical do verbo ouv-ir e não concretizou a alternância fonológica consonantal entre $[\mathrm{v}] \sim$ [s], para que a flexão assumisse sua forma padrão ouça (ou[s]a).

Dos dez verbos avaliados, neste estudo, os verbos "dizer" e "ter" foram os únicos que não sofreram nenhuma vez, durante a coleta de dados, o fenômeno da regularização. Os verbos "fazer" e "poder" exibiram baixo índice de conjugações com morfemas regularizados. Os demais verbos, entretanto, apresentaram um número elevado de flexões não padrão, regularizadas.

Tendo em vista que a aplicação dos recursos contou com um intervalo de um mês, entendemos que as repetições das formas regularizadas se mantiveram nas conjugações produzidas pelos sujeitos, em razão do processo da aquisição morfofonológica do sistema verbal irregular da língua não se encontrar plenamente dominado na gramática dessas crianças. O período de um mês entre as gravações é mais um argumento que salienta o fato de que os informantes deste estudo ainda estão em fase de aquisição do sistema verbal, visto que manifestaram os morfemas regularizados em ambas as coletas de dados.

Ressaltamos, ainda, que não se observam diferenças discrepantes entre os dados dos dois instrumentos, em virtude de que os sujeitos, em sua maioria, produziram formas não padrão para os mesmos verbos em ambos os instrumentos, salvo em raros casos em que realizaram o processo de regularização para algum verbo apenas em um dos instrumentos, como é o caso dos verbos "fazer" e "trazer", os quais foram regularizados apenas no segundo instrumento. 
A frequência verbal é outra variável que corrobora o fato de as crianças além de produzirem regularizações, manifestarem superioridade do fenômeno no modo subjuntivo. Para Meira (2009) a expectativa é que o subjuntivo fosse mais usado com os verbos irregulares, em função da maior quantidade de material fonético envolvido na flexão modo-temporal.

Notamos que quanto menor é a frequência do uso do verbo, mais dificuldade para sua produção a criança tende a apresentar. O verbo fazer, por exemplo, apresenta-se como um dos verbos mais frequentes no input linguístico dos falantes de PB (ANDERSEN, 2008) e, de fato, foi, neste estudo, um verbo que dificilmente sofreu algum tipo de regularização pelos sujeitos observados. Afirmamos, sob esse viés que, predominantemente, nas formas do presente do subjuntivo ocorreu maior número de regularizações para as conjugações de verbos irregulares, por ser esse o tempo de uso menos frequente na língua.

A frequência verbal, portanto, foi fator que se mostrou de particular relevância às nossas análises. Nesse contexto, os dados evidenciam que a regularização se dá, de forma prevalente, em se tratando dos verbos menos frequentes no input linguístico dos informantes, conforme já apontava a pesquisa de Andersen (2008). A autora defende que há uma correlação positiva entre a frequência do input e a aquisição da linguagem, considerando que as palavras de alta ocorrência são reconhecidas mais rapidamente e com melhor precisão do que as palavras de baixa frequência. A seguir, no Quadro (1), apresentamos a listagem de frequência verbal, apontada pela autora:

\begin{tabular}{|l|l|l|l|}
\multicolumn{4}{c}{ Quadro 1 - Verbos mais frequentes no PB, a partir do DIF } \\
\hline $1^{\circ}$ ser & $6^{\circ}$ dizer & $11^{\circ}$ saber & $16^{\circ}$ falar \\
\hline $2^{\circ}$ ter & $7^{\circ}$ haver & $12^{\circ}$ querer & $17^{\circ}$ chegar \\
\hline $3^{\circ}$ ir & $8^{\circ}$ fazer & $13^{\circ}$ ficar & $18^{\circ}$ precisar \\
\hline $4^{\circ}$ estar & $9^{\circ}$ dar & $14^{\circ}$ achar & $19^{\circ}$ começar \\
\hline $5^{\circ}$ poder & $10^{\circ}$ ver & $15^{\circ}$ dever & $20^{\circ}$ olhar \\
\hline
\end{tabular}

Fonte: Andersen (2008)

Andersen (2008) analisa a aquisição dos primeiros verbos de uma informante (estudo de caso), até a idade máxima de 04 anos e conclui, firmando-se em 
Biderman (1996), que as flexões verbais que figuram entre as mais frequentes são, inicialmente, marcadas pelas formas do infinitivo, do imperativo, do gerúndio e da terceira pessoa do singular dos tempos presente, pretérito perfeito e imperfeito. Diante disso, destacamos que os verbos “ter, poder, dizer e fazer" estão entre os dez verbos mais frequentes do PB, sendo que também foram, neste estudo, os verbos que menos sofreram o processo de regularização verbal; indo-se além, verificamos, por exemplo, que os verbos "ter e dizer" não foram flexionados, nenhuma vez, de acordo com a forma não padrão (regularizada), enquanto que os verbos "poder e fazer" foram alvos de um número muito baixo de produções regularizadas.

A idade mostra-se, também, um fator necessário para as análises até aqui consideradas. A princípio, em relação à faixa etária, consideramos que, conforme a idade da criança avançar, menores serão os efeitos que a regularização de verbos irregulares irão produzir. Ainda assim, o fenômeno poderá ser notado nas crianças maiores, devido à associação de outras variáveis investigadas (modo subjuntivo, frequência verbal) no estudo e presentes na conjugação verbal irregular. Reiteramos o fato que a variável faixa etária se sobrepõe à variável escolaridade, já que a cada faixa etária corresponde um nível de adiantamento das crianças no Ensino Fundamental I.

Nesse ponto de análise, tecemos uma possível relação entre o fenômeno aqui estudado e o ensino de verbos nas escolas, em especial, referindo-se ao ensino dos modos Indicativo e Subjuntivo em se tratando, sobretudo, de verbos irregulares.

Os dados revelam que as crianças até seus nove anos de idade ainda estão em fase de aquisição verbal, e, sobretudo, apontam que quanto maior é o nível de instrução escolar (observem-se a tabela 4) dos sujeitos, menor será a porcentagem de regularizações realizadas. Esse fato indica que "a instrução formal da língua é um caminho facilitador para a aquisição da linguagem considerada de caráter tardio, como é o caso da aquisição verbal irregular do PB"' (GOULART, 2015, p. 134).

\footnotetext{
${ }^{3}$ Nesse âmbito da pesquisa, atualmente estamos investigando o processo de aquisição verbal irregular, considerando o fenômeno da regularização, por meio de novo estudo, que focaliza a investigação desse processo com idades mais avançadas e também com crianças que, ainda, não estão frequentando a escola.
} 
Tabela 4 - Análise em relação à faixa etária / Escolaridade- Instrumentos I e II Ocorrência do Processo - Faixa etária / Escolaridade- Instrumentos I e II

\begin{tabular}{|l|l|l|l|}
\hline FE 1 - 06 ANOS & FE 2 - 07 ANOS & FE 3 - 08 ANOS & FE 4 - 09 ANOS \\
\hline $\mathbf{2 4 , 7 0} \%$ & $24,25 \%$ & $18,67 \%$ & $12,45 \%$ \\
\hline
\end{tabular}

Fonte: A autora

Tal relação (idade-escolaridade) propõe que as formas verbais irregulares do PB são adquiridas conforme aumenta a exposição da criança ao sistema linguístico, por isso, quanto maior é a idade, menor será o índice de regularizações produzido pelos sujeitos. Aos 09 anos de idade, por exemplo, maior faixa etária e maior grau de instrução dos informantes, percebemos o menor indicador de realização de morfemas verbais regularizados.

É relevante pontuar, nesse âmbito, que trabalhando com a variável escolaridade atrelada à idade, consideramos que é a escola quem vai trabalhar com a estrutura verbal irregular da língua, ou seja, é por meio da escola que a criança vai conseguir completar seu processo de aquisição da classe irregular do PB, bem como estabelecer a relação morfofonológica necessária para que esse processo se concretize na fala das crianças.

Nessa perspectiva, Meira (2009, p. 17) conclui que "apesar de não constituir um estereótipo no Brasil, o uso do subjuntivo, por exemplo, parece ser afetado pela ação da escola", tendo em vista que os falantes dos níveis escolares mais elevados usam mais as formas do subjuntivo.

Pelos dados da Tabela 4, é interessante observar a pouca diferença percentual que mostram os resultados das faixas-etárias 1 e 2, as quais correspondem ao período em que as crianças ainda se encontram no processo de alfabetização, mostrando queda importante no percentual relativo à quarta faixa-etária, quando o avanço da escolarização exige que a criança esteja plenamente alfabetizada.

Possivelmente, o sistema verbal irregular é adquirido integralmente quando a criança se defronta com o ensino dos tempos e modos verbais na escola, os quais, em consonância com a grade curricular nacional, devem ser estudados nos $6^{\circ}$ e $7^{\circ}$ anos $\left(5^{\mathrm{a}} \mathrm{e}\right.$ $6^{\text {a }}$ séries); aqui, a grande maioria dos alunos encontra-se na idade de 10 a 12 anos. É nesse momento que o falante vai se deparar com as formas assumidas pelos verbos irregulares nos diferentes tempos e modos verbais e, assim, vai também começar a lidar 
frequentemente com as alternâncias consonantais envolvidas nessas conjugações, em especial no Presente do Indicativo e Presente do Subjuntivo, tempos que manifestam a alta complexidade dos processos morfofonológicos do PB. Aqui, reafirmamos a importância da variável escolaridade-idade para a estabilização da flexão irregular do PB.

Nessa perspectiva, defendemos, neste artigo, que um caminho facilitador da aquisição verbal irregular do PB, que se mostra altamente complexa e tardia para as crianças de 06 a 09 anos de idade, é possibilitar que a criança manipule formas verbais irregulares já nas séries iniciais do ensino, etapa em que ainda se encontram em aquisição da língua (GOULART, 2015), segundo os dados deste estudo.

Com isso, não estamos defendendo que a classe verbal irregular em si deva ser ensinada já nas séries iniciais, mas, sim, que o professor possa oportunizar momentos, em que, oralmente, a criança consiga manipular as formas verbais espontaneamente; assim, o aluno poderá também ir se familiarizando com os verbos de baixa frequência em seu input, de forma que, quando precise usar as flexões irregulares, já estejam, essas, integradas à sua gramática.

\section{Considerações finais}

Com esse artigo, delineamos a complexidade envolvida no processo de aquisição verbal da classe irregular do Português Brasileiro. Evidenciamos, a partir de dados obtidos em pesquisa com 16 alunos entre 06 e 09 anos de idade, que tal aquisição pode ser considerada de natureza tardia, tendo em vista que se configura em um fenômeno presente na fala das crianças, no mínimo, até os 09 anos de idade.

Os modos verbais (indicativo e subjuntivo), os quais estão intrinsicamente ligados a essa aquisição, revelam que, no uso da língua, suas particularidades podem ser consideradas como fatores condicionantes do processo de regularização dos verbos irregulares. A regularização é por sua vez, um fenômeno linguístico em que os verbos irregulares são conjugados pelo sujeito de maneira regular, ou seja, de acordo com a morfologia dos verbos regulares, que em PB, assumem a maioria da classe verbal. 
Por esse ângulo, o modo subjuntivo, o qual é marcado na língua, é um coeficiente que, segundo os dados deste estudo, revela maior índice de regularizações em crianças entre 06 e 09 anos de idade. Além disso, a frequência verbal é outro fator que contribui para que esse fenômeno aconteça e permita que a aquisição verbal se estenda até faixa etária maior que 06 anos de idade, na qual o sistema fonológico da criança considerada típica já está plenamente adquirido (LAZZAROTTO-VOLCÃO, 2009).

Nesse âmbito, a escola será a instituição capaz de contribuir significativamente para a efetivação da aquisição das alternâncias verbais irregulares, por conseguir possibilitar maior exposição dos sujeitos a toda essa complexidade, o que aumentará a experiência linguística dos sujeitos. Além disso, os sujeitos também estarão expostos a outras experiências linguísticas significativas, que favorecerão a aquisição dessas irregularidades, como os grupos de convivência não-formal, tendo em vista que a frequência linguística é um fator essencial à aquisição. No entanto, pontuamos que é a escola, a instituição formal, que apresentará para os alunos a estrutura verbal irregular, sendo que quanto maior o grau de ensino, maior também será o desenvolvimento da conjugação verbal irregular em conformidade com a forma padrão da língua.

Apontamos, ainda, que as conclusões apresentadas neste estudo acrescentam uma contribuição adicional à educação, precisamente ao ensino do português nas escolas, entendendo que, quanto maior vivência do uso da língua o professor oferecer, inclusive com possibilidades do uso de formas verbais em falas espontâneas, mais precocemente a criança poderá adquirir o sistema verbal padrão do $\mathrm{PB}$, considerando-se que os verbos mais frequentes em seu input parecem ser os mais facilmente adquiridos.

\section{Referências}

ANDERSEN, Elenice Maria Larrosa. Representações lexicais subjacentes: verbos e léxico inicial. ReVEL, v. 6, n. 1, 2008.

BIDERMAN, Maria Teresa Camargo. Léxico e vocabulário fundamental: ALFA, n. 40, 1996. 
CÂMARA JÚNIOR, Joaquim Mattoso. Uma forma verbal portuguesa: Estudo EstilísticoGramatical. Rio de Janeiro: Jornal do Comércio - Rodrigues \& Cia, 195. 100 p.

CÂMARA JÚNIOR, Joaquim Mattoso. Estrutura da língua portuguesa. 38 ed. Rio de Janeiro: Vozes, 1970. 124 p.

CÂMARA JÚNIOR, Joaquim Mattoso. Estrutura da língua portuguesa. Petrópolis: Vozes, 1994.

CASTILHO, Ataliba Teixeira de. Nova gramática do português brasileiro. São Paulo: Contexto, 2012.

FREITAG, Raquel Meister. Tempo na frase e tempo no texto: as teorias de Keichenbach e de Rojo e Veiga. Linguagem em (dis)curso - LemD, Tubarão, v. S., n. 2, p. 398-413, 2005.

GOULART, Tamires Pereira Duarte, A produção de formas verbais irregulares por crianças falantes do Português Brasileiro (PB). 2015. Dissertação (Mestrado em Linguística Aplicada)- UCPEL, Pelotas, 2015.

LAZZAROTTO-VOLCÃO, Cristiane. Modelo padrão de aquisição de contrastes: Uma proposta de avaliação e classificação dos Desvios Fonológicos. 2009.Tese (Doutorado em Letras) - UCPEL Programa de Pós-Graduação em Letras - Pelotas, 2009.

LORANDI, Aline. Formas morfológicas variantes na aquisição da morfologia: evidências da sensibilidade da criança à gramática da língua. Letrônica, v. 3, n. 1 , p. 81; julho 2010.

LORANDI, Aline. Formas morfológicas na gramática infantil: um estudo à luz da Teoria da Otimidade. 2006. Dissertação (Mestrado em Linguística Aplicada) PUCRS, Porto Alegre, 2006.

MEIRA, Vivian. O emprego do modo subjuntivo. In: LUCCHESI, D.; BAXTER, A.; RIBEIRO, I. (Orgs.) O português afro-brasileiro. Salvador: EDUFBA, 2009, p. 389-407. ISBN 978-85232-0875-2. Available from SciELO Books <http://books.scielo.org>.

SANTOS, Raquel; SCARPA, Ester. A aquisição da morfologia verbal e sua relação com o acento primário. Letras de Hoje. Porto Alegre: EDIPUC, v. 38, 2003.

SOUZA \& SILVA Maria Cecília; KOCH, Ingedore Villaça. Linguística aplicada ao português: Morfologia. 17 ed. São Paulo: Cortez, 2009.

REICHENBACH, Hans. The tenses of verbs. In: Elements of symbolic logic. New York: The MacMillan Company, 1947. 
YAVAS, F; CAMPOS, J. Aquisição da morfologia verbal do português como L1 e L2. Letras de Hoje. Porto Alegre: PUCRS, 1988.

Recebido em: 23/03/2017 Aprovado em: 19/09/2017

Universidade do Estado de Santa Catarina - UDESC Centro de Ciências Humanas e da Educação - FAED

Revista PerCursos Volume 18 - Número 37 - Ano 2017 revistapercursos@gmail.com 